\title{
Multiscale modelling of fuel cells and related energy conver- sion systems
}

\author{
Ilenia Rossetti ${ }^{1, *}$
}

\author{
Chemical Plants and Industrial Chemistry Group, Dip. Chimica, Università degli Studi di Milano, CNR- \\ SCITEC and INSTM Unit Milano-Università, via C. Golgi 19, 20133 Milano, Italy \\ * Correspondence: ilenia.rossetti@unimi.it
}

\begin{abstract}
Heat and power cogeneration plants based on fuel cells are interesting systems for energyconversion at low environmental impact. Different fuel cells have been proposed, but experimental testing rigs are expensive and the development of commercial systems is time consuming if based on fully experimental activities. Furthermore, tight control of operation of fuel cells is compulsory to avoid damage, which must be based on accurate models, able to predict the cell behaviour and prevent stresses and shut-down. Some selected examples of steady state, dynamic and fluid dynamic modelling of different types of fuel cells are proposed, mainly PEMFC and SOFC type. The general ideas behind the thermodynamic, kinetic and transport description are recalled, with some examples of models derived for single cells, stacks and integrated power co-generation units.
\end{abstract}

Keywords: Fuel cells modelling; Heat and power cogeneration; PEMFC; SOFC

Fuel cells (FCs) are electrochemical devices that allow the direct chemical-to-electric energy transformation with high efficiency (up to ca. $60 \%$, upgraded to ca. $85 \%$ if thermal energy can be recovered). In comparison, internal combustion engines are based on more conversion steps (chemical-thermal-mechanical-electrical) and thus are by far less efficient.

Different types of FCs are available, classified according to the electrolyte: alkaline (A), proton exchange membrane (PEM), phosphoric acid (PA), molten carbonate (MC), solid oxide (SO). The operating temperature is strictly related to the nature of the electrolyte and in turn affects the type of electrocatalyst allowed and the possible criticisms in their use [1]. For instance, in SOFC the electrolyte allows the transport of oxygen ions through the oxygen vacancies of the oxide. Such ionic mobility is significant at high temperature $\left(\mathrm{ca} .800^{\circ} \mathrm{C}\right)$, at which kinetics is very fast and allows relatively inexpensive catalysts, since their activity can be relatively small. This temperature range also allows the direct internal reforming of organic substrates, making superfluous the addition of a fuel processor to produce $\mathrm{H}_{2}$ as fuel for the FC. On the contrary, a PEMFC works with a membrane which transports protons, it must work in humid conditions and this limits the temperature of operation to max. $80^{\circ} \mathrm{C}$ (except the high temperature formulations). Such a low temperature also implies the use of a very active catalyst, typically based on $\mathrm{Pt}$, since thermal activation of the surface reactions is limited. As a consequence of low temperature of operation and of the noble metal catalyst, sulphur and $\mathrm{CO}$ tolerance of PEMFCs is very poor, needing a careful purification of the $\mathrm{H}_{2}$ feed. Indeed, $\mathrm{CO}$ adsorbs at low temperature over $\mathrm{Pt}$, imposing a tolerance of $<20$ ppmv of $\mathrm{CO}$ in the feed. Operation at higher temperature allows much higher $\mathrm{CO}$ concentration even allowing to avoid significant purification of the feed, because at higher temperature the adsorption is almost insignificant.

Due to the features of the various FCs the preferred use is also different. The high efficiency, fast start-up, long life (ca. $5000 \mathrm{~h})$ and high power density $\left(0.3-0.8 \mathrm{~W} / \mathrm{cm}^{2}\right)$ make 
PEMFC preferable for mobility applications, whereas high temperature FCs are best fitted for stationary applications. Examples of application of PEMFCs in vehicles are available from different suppliers, e.g. Toyota Mirai, Nikola One and Chevrolet Colorado ZH2. The size of PEMFC system is up to $250 \mathrm{~kW}$, less than $10 \mathrm{~kW}$ for single houses, ca. $50 \mathrm{~kW}$ for buildings.

As for stationary or large scale applications, FCs may be used as stand-alone devices or connected to the grid. This option is somehow more complex, since the FC supplies DC, that be converted to AC and conditioned to the voltage of the grid. Furthermore, sufficient stability of the cell should be ensured for grid connection. The development of simulation tools and models to predicts the transient and steady state behaviour of the cell is a precious contribution to predict the safe operating modes. Fault prediction is one of the major issues to improve system reliability, considering permanent (membrane deterioration, poisoning, leakage and cell aging), transient (flooding or drying) and external (cooling system, feed supply) faults. Furthermore, some cells such as PEMFC and SOFC are particularly sensitive to operating conditions. Modelling offers a method for improve the control, optimisation and reliability of these FCs.

In addition, models to describe the poisoning rate by $\mathrm{CO}$ and the consequent voltage losses and regeneration conditions are useful for performance monitoring and correction [2].

The phenomena underpinning FC operation and connection with an upstream fuel processor or a downstream user occur at very different time and length scales, requiring proper modelling tools to achieve the desired information. Careful validation against the basic kinetic, thermodynamic and electrochemical principles, as well as against experimental data is compulsory, but also the choice of the proper modelling methods is fundamental. Avery detailed review makes a comprehensive description of the available equations to compute transport phenomena, electrochemical thermodynamic and kinetics and cell performance [3]. The scheme of the interconnections between these modelling activities and the different time and length scales of each of them are sketched in Figures 1 and 2.

Figure 1: Modelling items in SOFCs. Reproduced from [3] under the Creative Commons Licence. 


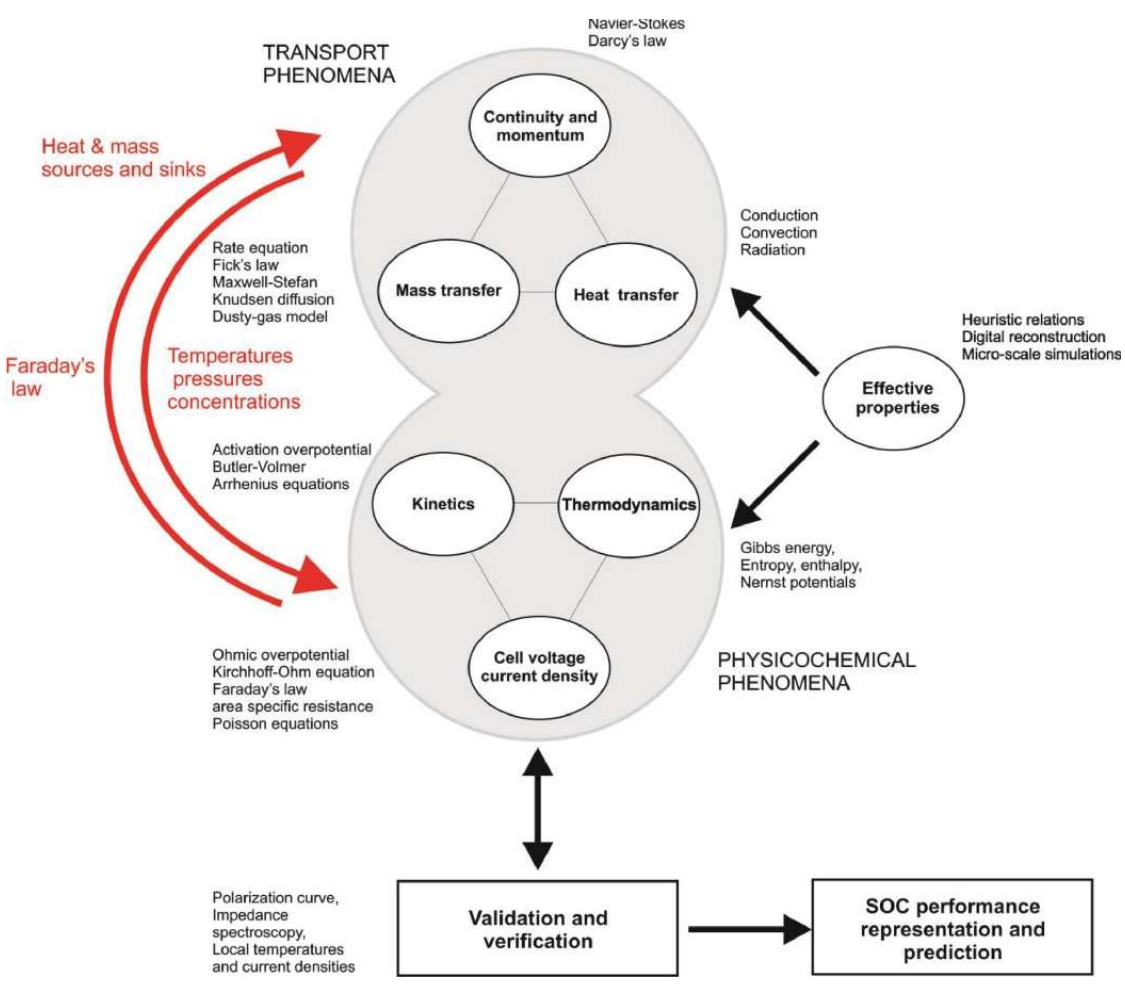

Figure 2: Time, frequency and length scales for the phenomena underpinning SOFC modelling. Reproduced from [3] under the Creative Commons Licence.

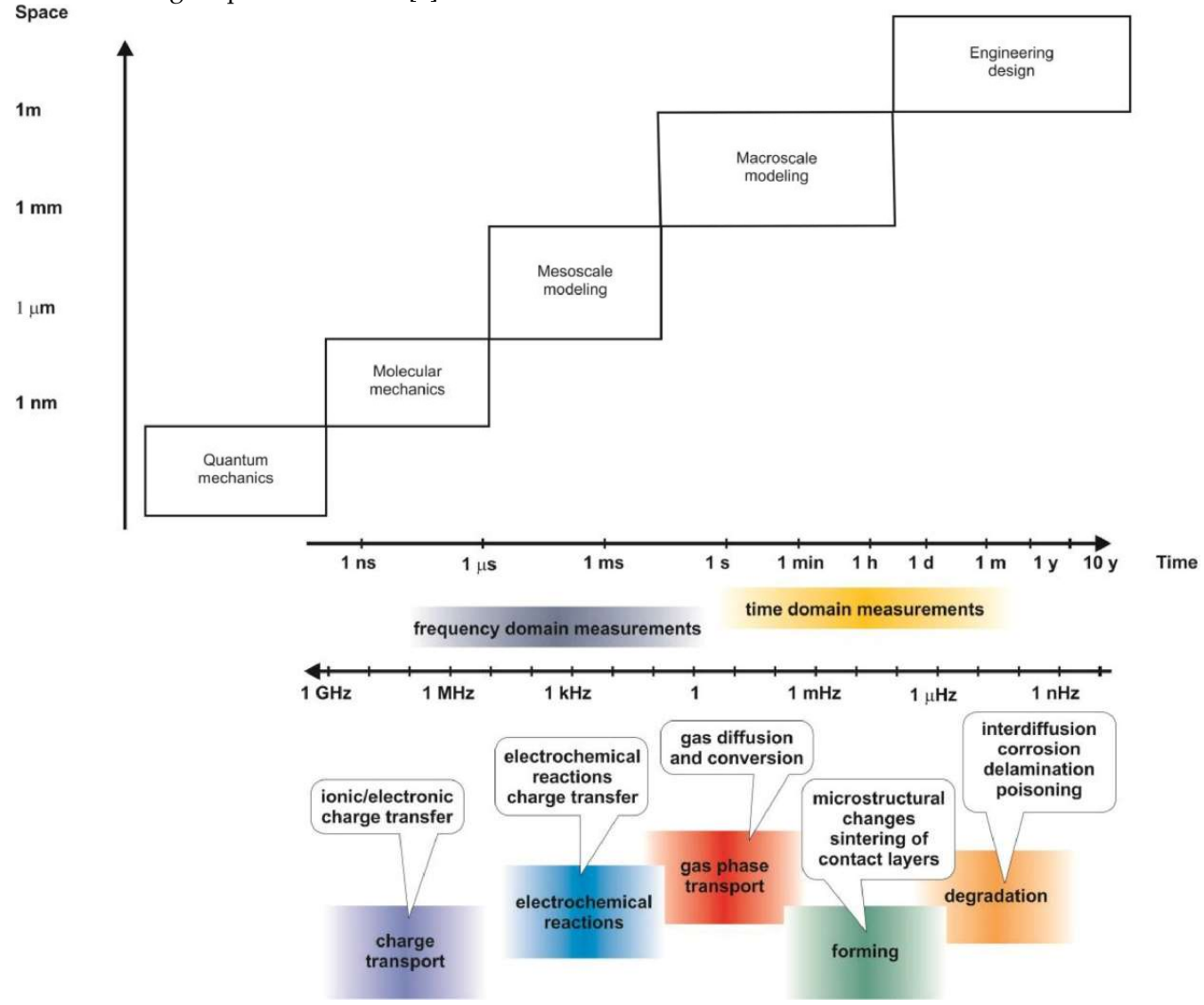


In this work recent modelling and simulation papers are reviewed to offer an up-todate panorama of the opportunities for multiscale modelling of FCs. Examples will be discussed from microscopic phenomena, such as the retrieval of transport parameters and kinetics, to the models to size and rate single cells, stacks and integrated power systems, including fuel processors and connection to the grid. The main features of the models are here presented and discussed, leaving the interested reader to the original reference for detailed description.

\section{Kinetics, thermodynamics and transport phenomena}

Computationally fast electrochemical models are useful to predict FC behaviour and provide the control logic. A 0-D thermodynamically consistent electrochemical model for PEMFC has been developed, including the transport of gaseous species along the channel and through gas diffusion layer (GDL) [4]. An optimal set of calibration parameters has been also retrieved on a physical consistent basis. Very good extrapolation capabilities for operation points outside the calibrated parameters space has been also demonstrated.

A mathematical model was built to evaluate the thermodynamic performance of a SOFC coupled with a thermoelectric generator and an absorption heat pump to recover the waste heat of SOFC exhaust gas [5].

A single-anode SOFC was tested to retrieve the characteristic curves to build a $2 \mathrm{D}$ steady-state simulation code in Fortran. This was based on a robust electrochemical kinetic model, with semi-empirical approach where the parameters derived from data fitting were used in physically derived equations [6]. To size and rate FCs, reliable kinetic models are needed, but they are multivariable device. Simulation involves nonlinear parameter estimation issues, often involving more than one local minima imposing the choice of robust optimisation algorithms $[7,8]$.

Gas-liquid mass transfer in the porous layers or in the current collectors has been modelled in the case of a PEMFC [9]. Liquid water, vapor, and non-condensable gasses in the pores were modelled to assess the best operating conditions and criticisms.

Mathematical modelling of a composite continuum-network formulation has been developed to describe species diffusion and convection in gas diffusion layers in PEMFC. This helps the fluid dynamic study of the system developing a control volume mesh to monitor anisotropic effective transport properties as diffusivity and permeability [10].

\section{Fuel cell and stacks}

A residential power generator $(60 \mathrm{~kW})$ based on a PEMFC stack was designed to operate at $75^{\circ} \mathrm{C}, 100 \%$ humidity (regulated through careful water management) and 3 bar pressure [11].

The behaviour of a PEMFC stack was investigated considering stability and efficiency under different conditions, to optimise the operating points during connection to the grid [12]. The equivalent circuit of the simulated PEMFC is reported in Figure 3. $\mathrm{V}_{0 \mathrm{C}}$ is the open circuit voltage, $\mathrm{T}_{\mathrm{d}}$ is the response time, $\mathrm{N}$ the number of cells, $\mathrm{I}_{\mathrm{fc}}$ and $\mathrm{V}_{\mathrm{fc}}$ the current and voltage of the cell, IE the exchange current.

Figure 3: Equivalent circuit of the simulated PEMFC, a) simplified, b) detailed. Reproduced from [12] under the Creative Commons Licence.

a) 


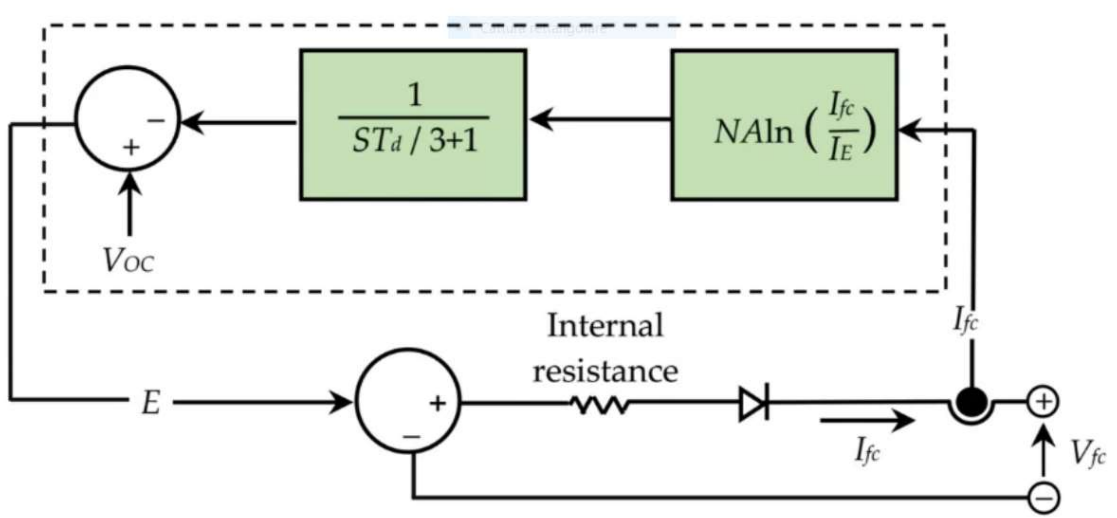

b)

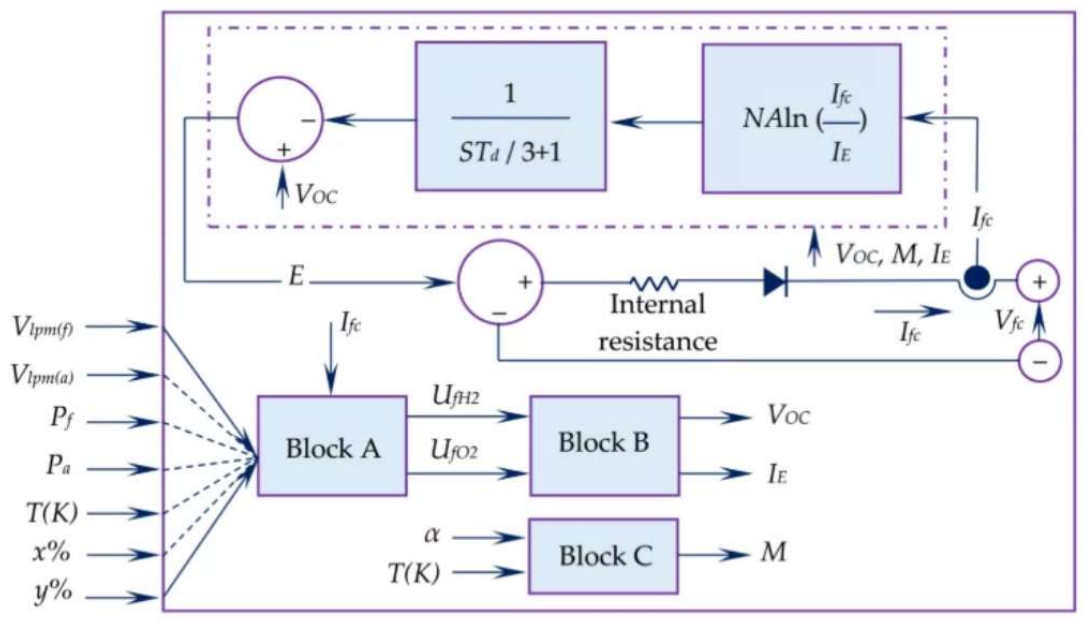

The detailed mathematical model is as follows [12]:

$$
\begin{gathered}
V_{0 C}=K_{C} E_{n} \\
I_{E}=\frac{z F k\left(P_{\mathrm{H}_{2}}+P_{\mathrm{O}_{2}}\right)}{R h} e^{\frac{-\Delta G}{R T}} \\
M=\frac{R T}{z \alpha F}
\end{gathered}
$$

Block A in the detailed scheme reported in Figure 3, calculates the conversion (U) of hydrogen and oxygen, based on the volumetric flow rates $(\mathrm{V})$, composition $(\mathrm{x} \%, \mathrm{y} \%)$, pressure of both gases $(\mathrm{P})$ and temperature $(\mathrm{T})$, assuming ideal gas behaviour.

$$
\begin{gathered}
U_{f_{H_{2}}}=\frac{n_{\mathrm{H}_{2}}^{r}}{n_{\mathrm{H}_{2}}^{i n}}=\frac{60,000 R T N I_{f c}}{z F P_{f u l} V_{l p m(f)} x^{\circ}} \\
U_{f_{\mathrm{O}_{2}}}=\frac{n_{\mathrm{O}_{2}}^{r}}{n_{\mathrm{O}_{2}}^{i n}}=\frac{60,000 R T N I_{f c}}{2 z F P_{a i r} V_{l p m(a)} y}
\end{gathered}
$$

The partial pressure of the different species and Nernst voltage are expressed as: 


$$
\begin{gathered}
P_{\mathrm{H}_{2}}=\left(1-U_{f_{\mathrm{H}_{2}}}\right) x \% P_{\text {fuel }} \\
P_{\mathrm{H}_{2} \mathrm{O}}=\left(w+2 y \% U_{f_{\mathrm{O}_{2}}}\right) P_{\text {air }} \\
P_{\mathrm{O}_{2}}=\left(1-U_{f_{\mathrm{O}_{2}}}\right) y \% P_{\text {air }} \\
E_{n}=\left\{\begin{array}{c}
1.229+(T-298) \frac{-44.43}{z F}+\frac{R T}{z F} \ln \left(P_{\mathrm{H}_{2}} P_{\mathrm{O}_{2}}^{1 / 2}\right) \text { when } \mathrm{T}<100{ }^{\circ} \mathrm{C} \\
1.229+(T-298) \frac{-44.43}{z F}+\frac{R T}{z F} \ln \left(\frac{P_{\mathrm{H}_{2}} P_{\mathrm{O}_{2}}^{1 / 2}}{P_{\mathrm{H}_{2} \mathrm{O}}}\right) \text { when } T>100^{\circ} \mathrm{C}
\end{array}\right.
\end{gathered}
$$

Block B calculates $V_{\text {oc }}$ and IE and block $C$ measures $\mathrm{M}$ (Tafel slope). $\alpha$ (charge transfer coefficient), $\Delta \mathrm{G}$ (activation barrier) and $\mathrm{K}_{\mathrm{c}}$ (voltage constant) depend on the polarisation curve at the rated operating conditions and on the variation of the gas pressures at varying temperature.

$$
\begin{aligned}
& U_{f_{H_{2}}}=\frac{\eta_{\text {rated }} \Delta h^{\circ}\left(\mathrm{H}_{2} \mathrm{O}(\text { gas })\right) N}{z F V_{\text {rated }}} \\
& U_{f_{\mathrm{O}_{2}}}=\frac{60,000 R T_{\text {rated }} N I_{\text {rated }}}{2 z F P_{a_{\text {rated }}} V_{\text {lpm }(a)_{\text {rated }}} x 0.21} \\
& K=\frac{V_{u}}{K_{c}\left(U_{f_{\mathrm{O}_{2}}(\text { peak })}-U_{f_{\mathrm{O}_{2}}(\text { rated })}\right)} \\
& E_{n}= \begin{cases}E_{n}-K\left(U_{f_{\mathrm{O}_{2}}}-U_{f_{\mathrm{O}_{2}}(\text { rated })}\right) & U_{f_{\mathrm{O}_{2}}}>U_{f_{\mathrm{O}_{2}}(\text { rated })} \\
E_{n} & U_{f_{\mathrm{O}_{2}}}<U_{f_{\mathrm{O}_{2}}(\text { rated })}\end{cases}
\end{aligned}
$$

Voltage and $\mathrm{O}_{2}$ utilisation vs. time are represented in Figure 4 [12].

Figure 4: Profiles of voltage and $\mathrm{O}_{2}$ utilisation vs. time. Reproduced from [12] under the Creative Commons Licence.

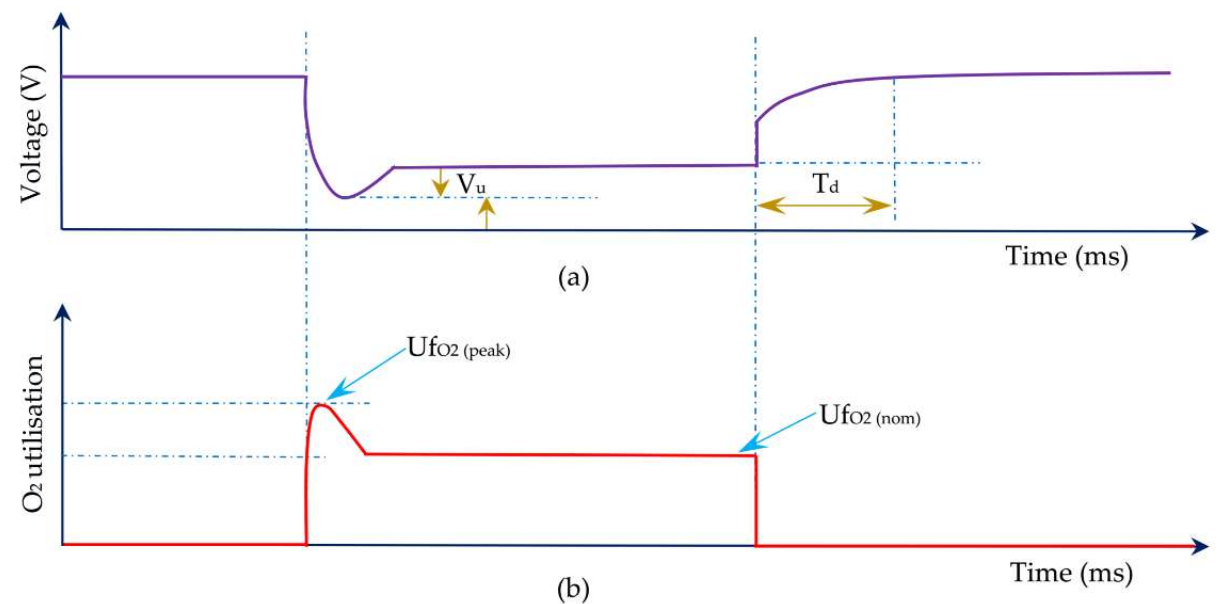

Overall the scheme of the FC stack, including 45 cells, and the details of the block for connection to the grid are exemplified in Figure 5 [12]. 
Figure 5: a) PEMFC scheme and b) blocks for connection to the grid. Reproduced from [12] under the Creative Commons Licence.

a)

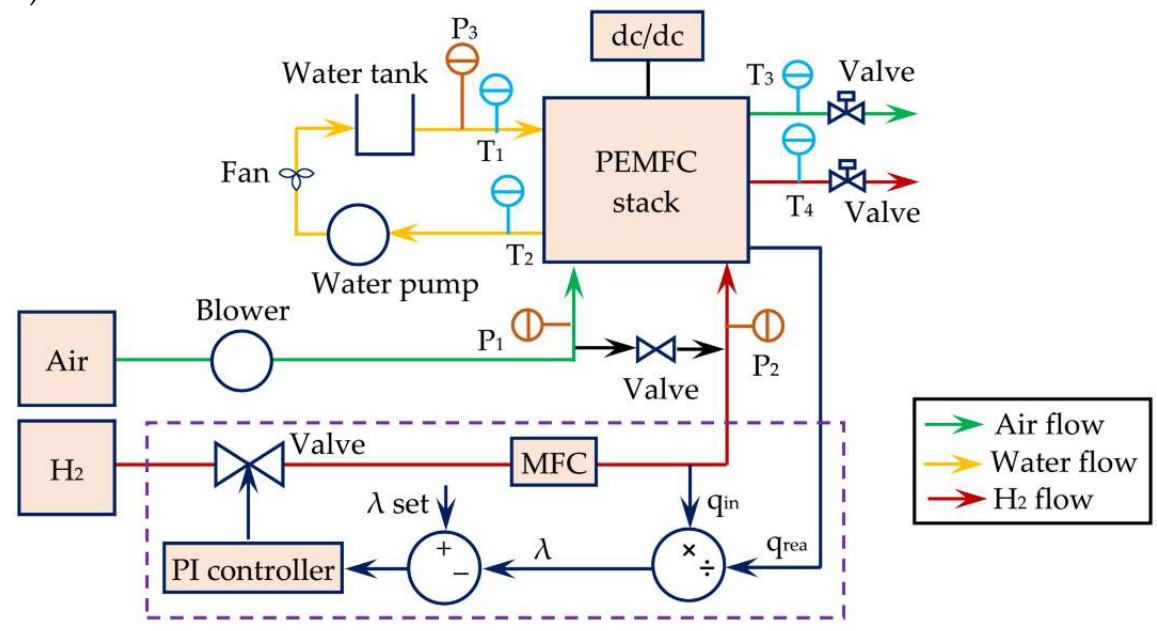

b)

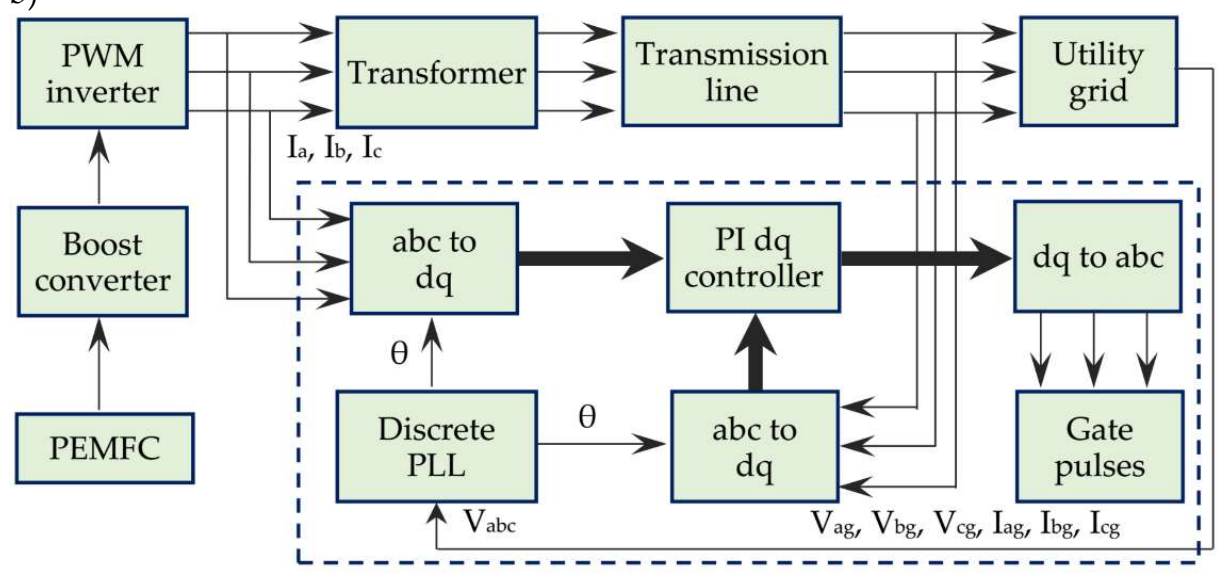

The simulation showed that variable pressure of air did not affect significantly fuel usage, but strongly the efficiency. Critical pressures have been determined to ensure stable operation as 0.8 bar for air and 1.4 for the fuel. The latter parameter affected both fuel consumption and efficiency [12].

The performance of a PEMFC depends on many structural and working parameters (flowrates, pressure and relative humidity, membrane hydration, T and P of the cell, etc.), so that the development of robust models to optimise its operating optimum saves precious time during the set up of the device $[8,13,14]$. Nevertheless, the complexity of the governing equations and the multiple dependence from so many variables makes the modelling activity very hard.

As usual, models can be classified as empirical, semi-empirical and mechanistic, with a growing degree of complexity and accuracy/robustness of representation of the phenomena. In the present case purely empirical models are very weak, while the mechanistic ones are usually too complex and computationally expensive due to the high number of factors and the algebraic-differential nature of the problem [8]. Overall, semi-empirical models may be a reasonable compromise, with regression of some unknown quantities and inclusion/solution of the fundamental equations. Among these, the zero-dimensional steady state models, such as the Generalised Steady State Electrochemical Model (GSSEM), have been mostly employed due to their relative simplicity and versatility [15]. However, the need to retrieve some of the parameters brings about an additional problem, the selection of the optimization algorithm. Usually the characteristic I-V curve of the cell 
is fitted through the model to accomplish the non-linear regression of the missing parameters. Therefore, the typical objective function is:

$$
F_{\text {obj }}=\sum_{j=1}^{N}\left(E_{\text {cell }}^{\text {calculated }}-E_{\text {cell }}^{\text {experimental }}\right)^{2}
$$

The calculated cell potential includes all the hypotheses and formulations of the model proposed and the unknown parameters to be regressed. The search algorithms applied to FCs are different, e.g. genetic algorithm [16], artificial neural network [17], artificial bee colony [18], harmony search [19], whale optimization algorithm [20] and some hybrid formulations. Often, the physical meaning of the retrieved parameters is not demonstrated when the optimisation search algorithm is insufficiently robust [8]. Typically, they fail in description of the electrochemical phenomena, evaluation of cell resistance and reversible voltage, computation of the concentration losses and estimation of the effect of operating parameters.

Some of the features and criticisms of GSSEM models are discussed in the following, full details can be found in the references $[8,15]$.

The cell voltage is calculated as:

$$
\begin{gathered}
E_{\text {cell }}=E_{\text {Nernst }}-\eta_{\text {Act }}-\eta_{\text {Ohm }}-\eta_{\text {Conc }} \\
\eta_{\text {Act }}=\xi_{1}+\xi_{2} T+\xi_{3} T \ln \left(C_{O 2}\right)+\xi_{4} T \ln (I)
\end{gathered}
$$

Where ENernst is the thermodynamic potential, while the $\eta$ terms represent the losses due to activation, ohmic and concentration effects, $\mathrm{T}(\mathrm{K})$ is the cell temperature. A scheme of the polarisation curve of a PEMFC is exemplified in Figure 6.

Figure 6: Polarisation curve of a PEMFC. Reproduced from [13] under the Creative Commons Licence.

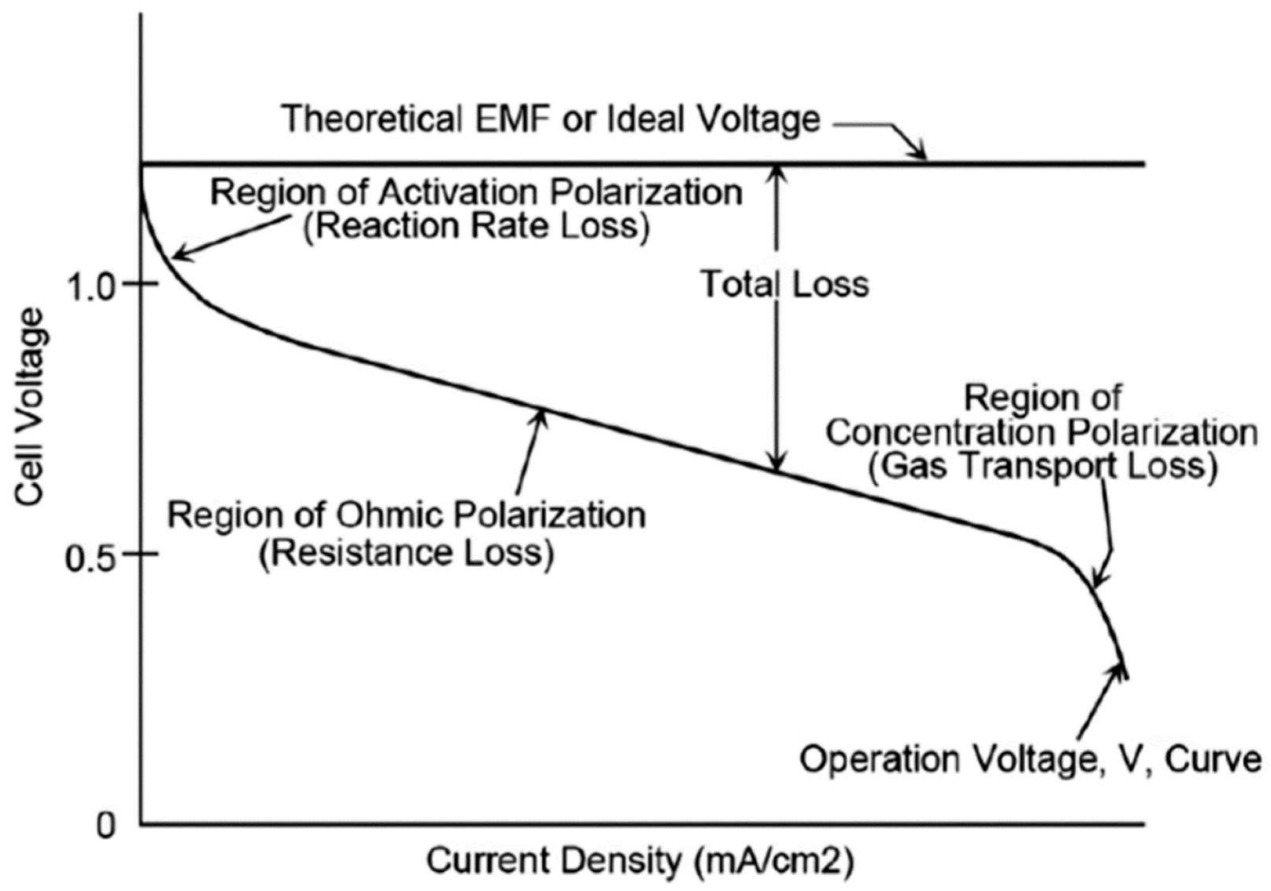

$\xi_{\mathrm{i}}$ are parameters that can be derived in principle from thermodynamic and kinetic mechanistic equations and have a precise physical meaning. 
For instance,

$$
\begin{gathered}
\xi_{3}=\frac{R\left(1-\alpha_{c}\right)}{\alpha_{c} n_{e} F} \\
\xi_{4}=-\left(\frac{R}{2 F}+\frac{R}{\alpha_{c} n_{e} F}\right)
\end{gathered}
$$

with $\mathrm{R}$ the gas constant $(8.3143 \mathrm{~J} / \mathrm{mol} \mathrm{K}), \mathrm{F}$ the Faraday constant (96487 As/mol), ne the number of electrons per mole and $\alpha_{c}$ the charge transfer coefficient of the cathode, which can be either calculated from the values of $\xi_{3}$ or $\xi_{4}$, as regressed from the model. A consistent set of parameters would return similar values when calculating $\alpha_{c}$ from both parameters, which does not happen in most cases, as well examined in $[8,13]$.

$$
\begin{gathered}
E_{\text {Nernst }}=1.229-0.85 \times 10^{-3}(T-298.15)+4.31 \times 10^{-5} T\left[\ln p_{H 2}+0.5 \ln p_{O 2}\right] \\
p_{H 2}=0.5\left(R H_{a} P_{w}^{s a t}\right)\left[\frac{1}{\left.e^{\frac{-1.635 i}{T^{1.334}}} \times \frac{1}{\frac{R H_{a} P_{w}^{s a t}}{P_{a}}}-1\right]}\right. \\
p_{O 2}=\left(R H_{c} P_{w}^{\text {sat }}\right)\left[\frac{1}{\left.e^{\frac{-4.192 i}{T^{1.334}}} \times \frac{1}{\frac{R H_{c} P_{w}^{s a t}}{P_{c}}}-1\right]}\right.
\end{gathered}
$$

Where $\mathrm{pH}_{2}$ and $\mathrm{pO} 2$ are the effective partial pressures of the two species, $\mathrm{P}_{\mathrm{i}}$ are the inlet pressures at the anode and cathode, $\mathrm{P}_{\mathrm{w}}$ sat is the vapor pressures, $\mathrm{RH}_{\mathrm{i}}$ are the relative humidities of the anode and cathode side and $i$ is the current density of the cell.

The voltage drops are differently computed.

The activation term is due to the slow kinetics which causes overpotentials and lower current densities. The current density can be calculated through the Bulter-Volmer equation (io is the exchange current density, i.e. the rate of the reactions at equilibrium when the net current is nil, $\mathrm{nF}$ the charge transferred, $\alpha_{i}$ the charge transfer coefficient for both reactions and $\mathrm{E} / \mathrm{E}_{\mathrm{r}}$ the actual and equilibrium potentials, $\mathrm{k}_{\mathrm{B}}$ and $\mathrm{h}$ the Boltzmann and Planck constants, $C_{i}$ the surface concentration of the reacting compounds and $\Delta G$ the Gibbs free energy):

$$
\begin{gathered}
i=i_{0}\left[\exp \left(\frac{-n F \alpha_{R e d}\left(E-E_{r}\right)}{R T}\right)-\exp \left(\frac{-n F \alpha_{O x}\left(E-E_{r}\right)}{R T}\right)\right] \\
i_{0}=n F k_{0} C_{O x} \exp \left(\frac{-\Delta G_{c h, \text { Red }}}{R T}\right) \exp \left(\frac{-n F \alpha_{\text {Red }} E_{r}}{R T}\right) \\
=n F k_{0} C_{\text {Red }} \exp \left(\frac{-\Delta G_{c h, O x}}{R T}\right) \exp \left(\frac{-n F \alpha_{O x} E_{r}}{R T}\right) \\
k_{0}=\frac{k_{B} T}{h}
\end{gathered}
$$

The current densities at the cathode and anode can be calculated as follows and consequently the activation losses, higher for the cathode than for the anode:

$$
\begin{gathered}
i_{c}=i_{0, c} \exp \left(\frac{-n_{c} F \alpha_{R e d, c}\left(E_{c}-E_{r, c}\right)}{R T}\right) \\
i_{a}=i_{0, a} \exp \left(\frac{-n_{a} F \alpha_{O x, a}\left(E_{a}-E_{r, a}\right)}{R T}\right) \\
\eta_{A c t, c}=E_{r, c}-E_{c}=\frac{R T}{n_{c} F \alpha_{R e d, c}} \ln \left(\frac{i}{i_{0, c}}\right) \\
\eta_{A c t, a}=E_{a}-E_{r, a}=\frac{R T}{n_{a} F \alpha_{O x, a}} \ln \left(\frac{i}{i_{0, a}}\right) \\
\eta_{A c t}=\eta_{A c t, c}+\eta_{A c t, a}
\end{gathered}
$$

The reversible potentials for hydrogen oxidation at the anode and oxygen reduction at the cathode are respectively $0 \mathrm{~V}$ and $1.23 \mathrm{~V}$ at $\mathrm{T}=25^{\circ} \mathrm{C}$ and $\mathrm{P}=1 \mathrm{~atm}$. 
The ohmic losses include the resistance towards electron and proton transport:

$$
\begin{gathered}
\eta_{\text {ohm }}=A i\left(R_{M}+R_{C}\right) \\
R_{M}=\frac{\rho_{M} l}{A} \\
\rho_{M}=\frac{181.6\left[1+0.03 i+0.062\left(\frac{T}{303}\right)^{2} i^{2.5}\right]}{(\lambda-0.634-3 i) \exp \left[4.18\left(\frac{T-303}{T}\right)\right]}
\end{gathered}
$$

indicating with $\mathrm{A}$ the active area and with $\mathrm{R}_{\mathrm{i}}$ the resistances towards electron flow (usually unknown and to be retrieved by regression) and the membrane one, $l$ is the thickness of the membrane and $\rho \mathrm{M}$ is its specific resistivity, reported in the above example for a Nafion membrane, whose resistivity is strongly dependent on its water content $\lambda$.

The concentration voltage drop is instead related to mass transfer limitations, that may limit the feed of reactants to the electrodes surface, causing a voltage loss.

$$
\eta_{\text {Conc }}=-B \ln \left(1-\frac{i}{i_{L}}\right)
$$

iL being the limiting current density and B another unknown parameter of the cell to be retrieved via regression. In the optimisation it is better to set the upper and lower limits for the search of the different parameters. For instance $\alpha_{\mathrm{I}}=0.2-2, \mathrm{C}_{\mathrm{H}^{+}}=10^{-11-10^{-4}}, \Delta \mathrm{Gch}_{\mathrm{c}, \mathrm{i}}=10-$ $70 \mathrm{~kJ} / \mathrm{mol}, \mathrm{R}_{\mathrm{C}}=1-810^{-4} \Omega, \lambda=10-24$ and $\mathrm{B}=0.0136-0.5$, as suggested in [8].

Once the voltage of a single cell has been modelled, the voltage of the stack can be calculated by multiplying the one of the single cell by the number of cells of the stack. The total power output is computed from the product of the current and the voltage of the stack [13].

Artificial Neural Network was used as robust search algorithm to extract the FC parameters in [21], a slime mould optimisation algorithm was applied in [7], a flower pollination algorithm was applied in [22].

A similar model was applied to interpret the experimental data collected over a 30 cells stack by varying temperature, pressure and relative humidity [23]. The model correctly represented the stack operation within ca. 10\% error. A decrease of the activation losses was evident at increasing temperature due to the increase of the exchange current density. Also mass transfer limitations decreased with increasing temperature. An increase of pressure improved the operation due to higher partial pressures of both the reactants. The effect of relative humidity was more sensitive to the cathode than the anode due to the higher flowrate. Overall, the polarisation curves were correctly represented by the model, though with a systematic voltage overestimation by ca. $10 \%$ due to simplified model assumptions.

A model implemented in Matlab $^{\odot}$ has been developed for a PEMFC and for an integrated electrolyser/fuel cell, with economic analysis [24]. The model develops through mass balances at the anode, cathode and membrane, as synthetically described below. The 1-D model assumes uniform distribution of reactants and current. At the anode, $\mathrm{H}_{2}$ is the only species considered, considering its inlet flow and the one consumed, quantified by the Faraday equation:

$$
\begin{gathered}
\dot{N}_{H 2, \text { cell }}=\dot{N}_{H 2, \text { in }}-\dot{N}_{H 2, \text { cons }} \\
\dot{N}_{H 2, \text { cons }}=\frac{n I}{2 F} \\
\dot{N}_{H 2, \text { in }}=\frac{S_{H 2} n I}{2 F}
\end{gathered}
$$

where $\mathrm{n}$ is the number of cells in the stack, I the current intensity and $\mathrm{S}_{\mathrm{H} 2}$ the stoichiometric ratio.

At the cathode, besides the oxygen balance, water must be also considered. 


$$
\begin{gathered}
\dot{N}_{O 2, \text { cell }}=\dot{N}_{O 2, \text { in }}-\dot{N}_{O 2, \text { cons }}-\dot{N}_{O 2, \text { out }} \\
\dot{N}_{O 2, \text { cons }}=\frac{n I}{4 F} \\
\dot{N}_{O 2, \text { in }}=\frac{S_{O 2} n I}{4 F} \\
\dot{N}_{H 2 O, \text { cathode,cell }}=\dot{N}_{H 2 \text { Ovap, in }}+\dot{N}_{H 2 O, p r o d}+\dot{N}_{H 2 O, \text { membr,cell }}-\dot{N}_{H 2 O, \text { out }} \\
\dot{N}_{H 2 O v a, \text { in }}=\frac{S_{O 2} n I}{4 F} \frac{R H_{c} P_{\text {sat }}}{P_{\text {out }, \text { cell }}-R H_{c} P_{\text {sat }}}
\end{gathered}
$$

where $\mathrm{So}_{2}$ the stoichiometric ratio, $\mathrm{RH}_{\mathrm{c}}$ is the relative humidity at the cathode and $\mathrm{P}_{\text {sat }}$ is the saturation pressure for water, calculated as a function of temperature. The total flowrate at the cathode is the sum of that of oxygen and water [24].

As for the membrane, no crossover of oxygen and hydrogen is considered, but only protons and water transport. They are modelled considering different mechanisms: electro-osmotic drag (eod), diffusion (diff), pressure gradients and thermo-osmosis, of which only the first two are considered significant.

$$
\begin{gathered}
\dot{N}_{H 2 O, \text { membr,cell }}=\dot{N}_{H 2 O, \text { eod }}-\dot{N}_{H 2 O, d i f f} \\
\dot{N}_{H 2 O, e o d}=\frac{n_{d} i A}{F} \\
n_{d}=0.0029 \lambda_{\text {membr }}^{2}+0.05 \lambda_{\text {membr }}-3.410^{-19} \\
\dot{N}_{H 20, \text { diff }}=D_{H 2 O}\left(\frac{C_{H 2 O, a}-C_{H 2 O, c}}{\text { thickness }}\right) A
\end{gathered}
$$

where I is the current intensity, A the active area, $\mathrm{nd}_{\mathrm{d}}$ the eod coefficient, $\lambda_{\text {membr }}$ the water content of the membrane and $\mathrm{D}_{\mathrm{H} 2 \mathrm{O}}$ the water diffusion coefficient, quantified as described in [24].

The scheme of the model is reported in Figure 7. Costs of the order of $610^{4}$ US\$ have been estimated, which is comparably high with respect to rival technologies.

The effect of gas crossover is of course important, almost unavoidable in PEMFC and attempts to consider it should be done. $\mathrm{N}_{2}$ and $\mathrm{O}_{2}$ flow to the anode and $\mathrm{H}_{2}$ to the cathode leading to parasitic reactions, mixed potentials and an overall reduction of efficiency. Furthermore it leads to degradation due to the formation of pinholes. An example of modelling gas crossover in HT-PEMFC is reported by Chippar and Ju [25].

Figure 7: Synopsis of the model of a PEMFC. Reproduced from [24] under kind permission by Elsevier. 


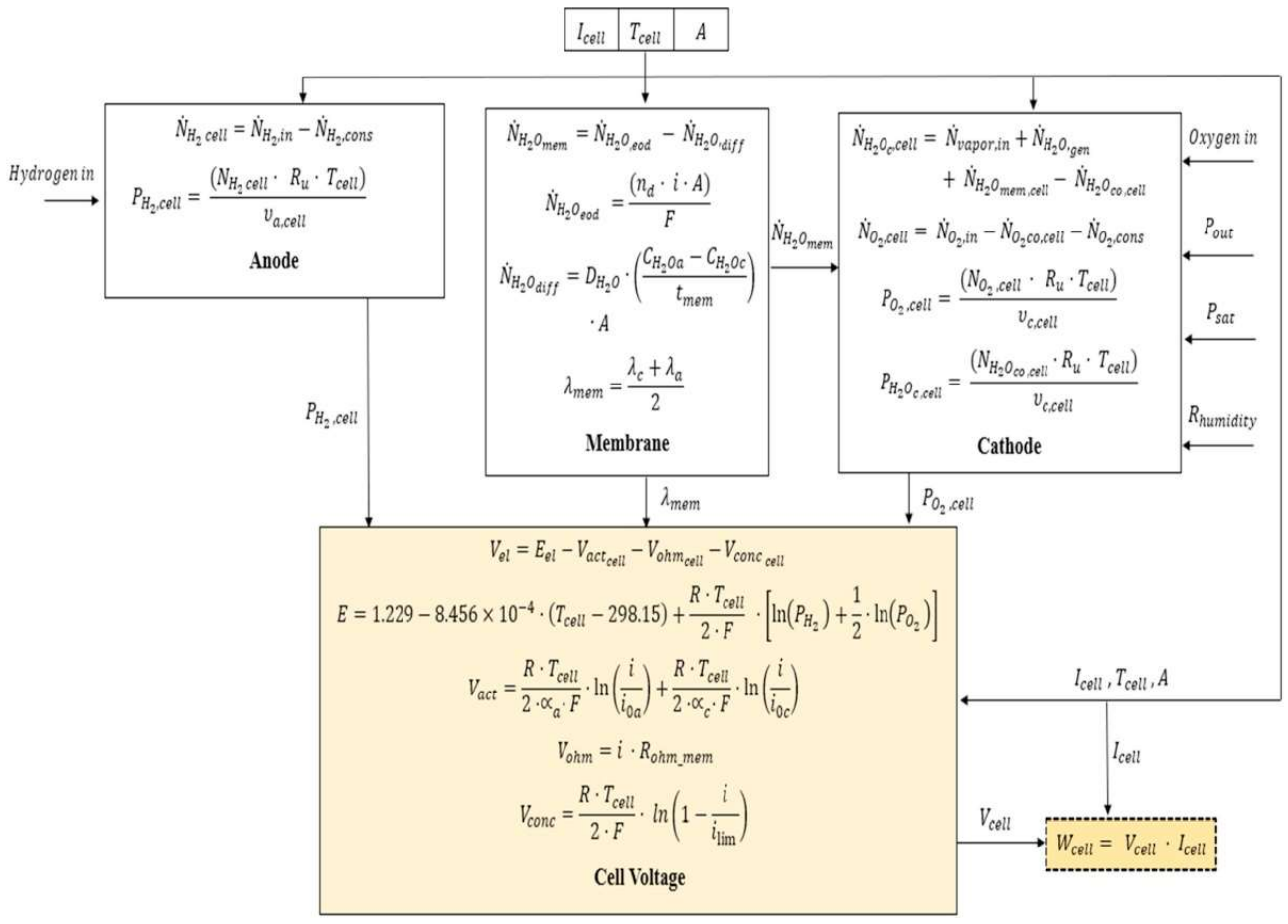

A very accurate steady state model of a SOFC tube, based on experimental data, has been developed in [26], returning in general a $1 \%$ error (max deviation $8 \%$ ). The model included mass and heat balances for both the solid and fluid ensuring a satisfactory account also of the thermal management of the system.

\section{Failure modelling}

P. Costamagna et al. widely studied in the last decade fuel cell systems, often based on SOFCs, developing specific models for the description of stacks and electrodes, integrated fuel processors and more recently their failure modes. In particular, two classical failure detection approaches, based on fault signature matrix or on data with statistical classification, were applied independently or combined. The random forest classification was used to select regular and faulty modes. A hybrid approach coupling a model-based scheme with a statistical classifier showed the most effective [27-30].

The degradation modes for SOFC have been extensively analysed by Eichhorn Colombo and Kharton [31], including coking, sulfur poisoning, formation of local hot spots due to excessive current densities, frequent power cycling. In order to model the probability of failure, or in other terms the reliability of the system, a hierarchy of analysis is proposed as in Figure 8 and the failure probability is correlated with the stresses of the cell or stack, which determines the correlation between current density and failure probability.

Figure 8: Block diagram for the development of failure models. Reproduced from [31] by kind permission of Elsevier. 


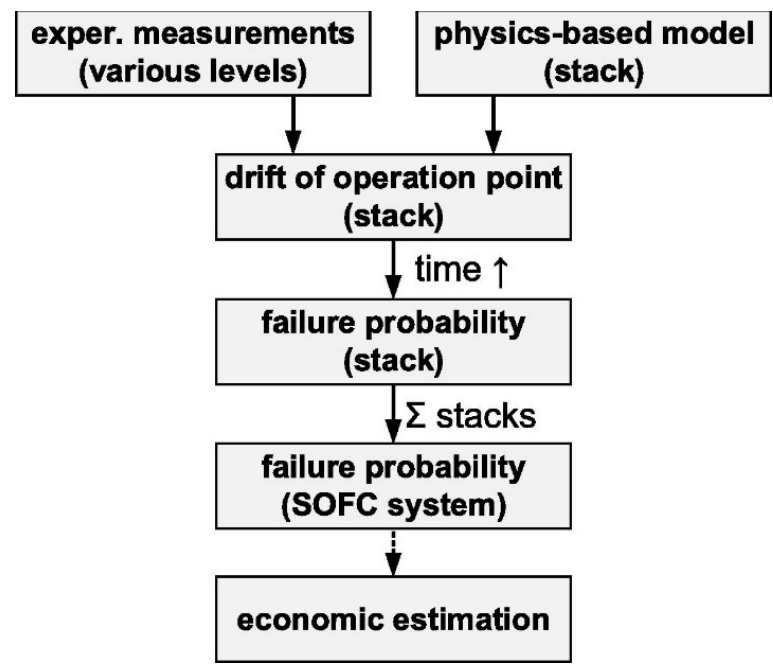

An empirical degradation rate can be calculated and affects the cell voltage during time:

$$
\begin{gathered}
\dot{r}_{\text {deg }}=f(i, T) \\
E=E_{\text {Nernst }}-\eta_{\text {total }}\left(1+\dot{r}_{\text {deg }} d t\right)
\end{gathered}
$$

The model can be integrated with a non linear equation solver to build the expected cell behaviour at a given time, building for instance the polarisation curve including the degradation of the cell (Figure 9).

Figure 9: Principal current density-voltage relationship for a SOFC, including deactivation. Reproduced from [31] by kind permission of Elsevier.

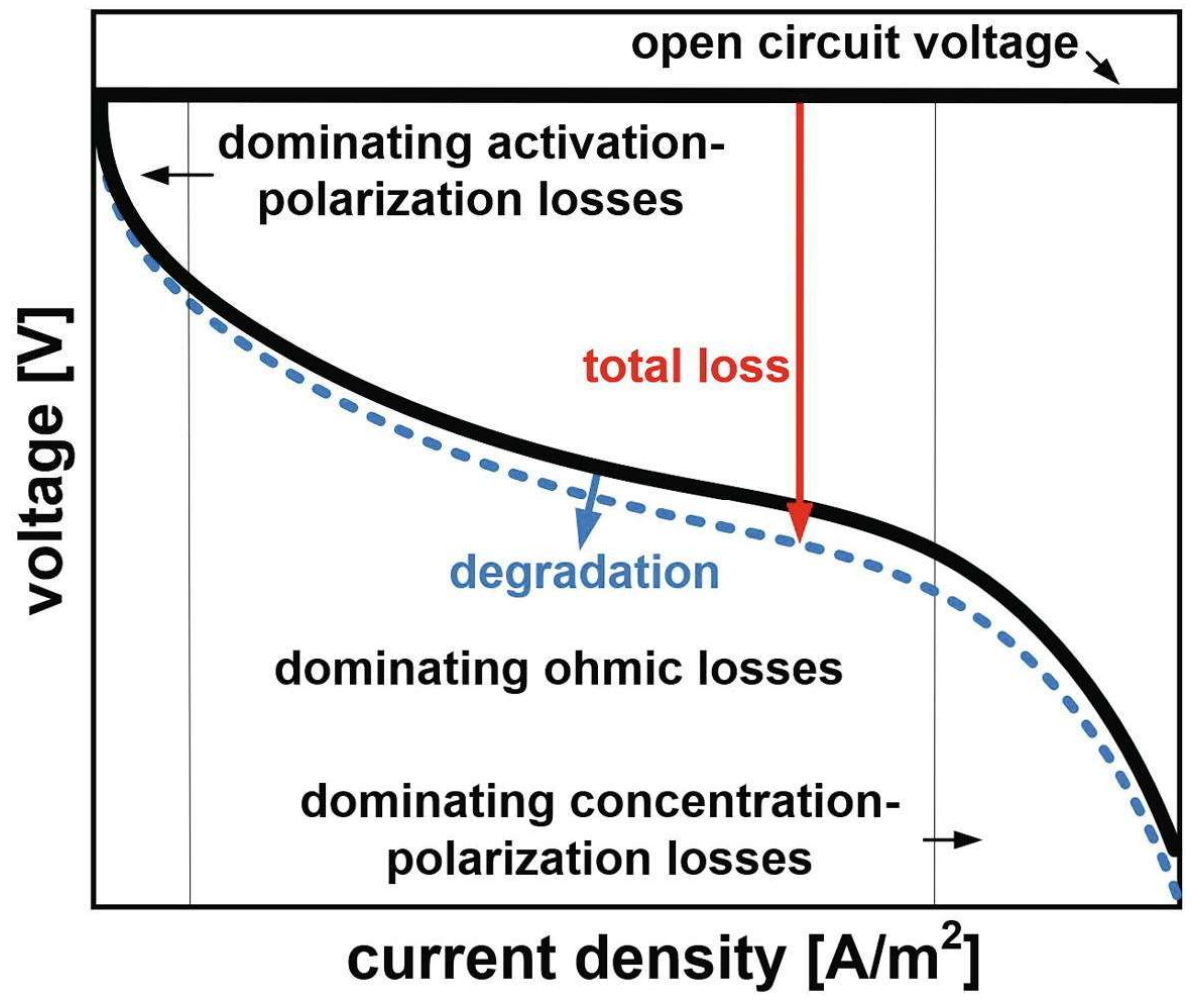


Different formulations can be given for the degradation rate, either derived from experimental data, or more easily visualised in terms of virtual age, which quantifies the extent of loss of each element as a function of current density, voltage or operating temperature [31]. Based on statistics, if a system is constituted of components connected in series, the system fails if any of the component fails. If they are connected in parallel, failure occurs when all the components fail. If a SOFC system is based on $\mathrm{n}$ independent identical stacks, k stacks being in operation occurs with a probability of:

$$
\begin{gathered}
\operatorname{Pr}=\left(\begin{array}{l}
n \\
k
\end{array}\right)\left(1-P_{f}\right)^{k} P_{f}^{n-k} \\
\left(\begin{array}{l}
n \\
k
\end{array}\right)=\frac{n !}{k !(n-k) !}
\end{gathered}
$$

Where $P_{\mathrm{f}}$ is the failure probability of a stack. The reliability of the system is calculated as:

$$
\text { Rel }=\sum_{i=k}^{n} \operatorname{Pr} \quad k \leq i \leq n \text { operating stacks }
$$

Overall, at constant current density SOFC degradation rate increases with operating temperature, while at constant temperature increases with the current density. The failure probability can be plotted vs. the virtual age of the system, as in Figure 10.

Figure 10: Failure probability function in comparison to that from [32]. Reproduced from [31] by kind permission of Elsevier.

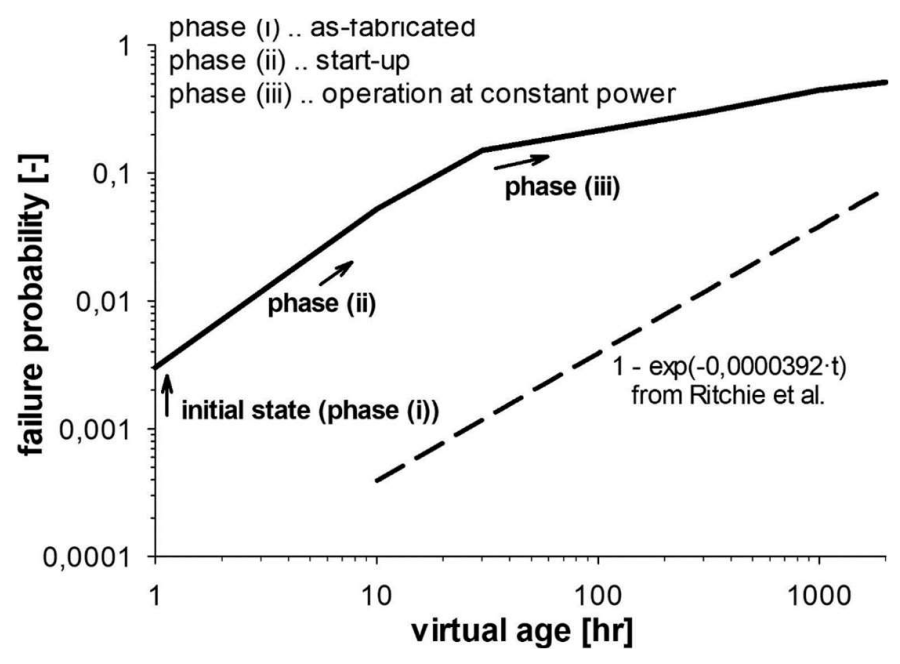

\section{Dynamic modelling}

In addition to steady state modelling, dynamic simulation is important to highlight the transient behaviour of the system. Different models have been briefly reviewed in [9] and Matlab ${ }^{\odot}$ and Simulink ${ }^{\odot}$ tools are often used to this scope, as detailed in [13]. 
Besides the computation of all the variables described for steady state models, dynamic modelling adds a dynamic computation of the activation losses and of cell thermodynamics due to the formation of a charge double layer (CDL). The following time-dependent equations add:

$$
\begin{aligned}
& \frac{d \eta_{A c t}}{d t}=\frac{i}{C}-\frac{\eta_{A c t}}{R_{C} C} \\
& R_{c}=\frac{\eta_{A c t, 0}+\eta_{C o n c}}{i}
\end{aligned}
$$

Where $R_{c}$ sums the steady state losses for activation and concentration and $C$ is the double layer charge [13]. Furthermore, the temperature of the cell does not remain constant and its value affects most of the variables of the model. Its variation with time is:

$$
C_{T} \frac{d T}{d t}=i\left(E_{\text {Nernst }}-E_{\text {cell }}\right)-H\left(T_{\text {cell }}-T_{f}\right)
$$

Where $\mathrm{C}_{\mathrm{T}}$ is the thermal capacitance, $\mathrm{H}$ the global heat transfer coefficient, $\mathrm{T}_{\mathrm{f}}$ the reference temperature and $\mathrm{T}_{\text {cell }}$ the lumped temperature of the FC [13].

For instance, a dynamic model of a Horizon H-500 PEMFC has been described [33], where the double layer formations has been described as a capacitor. A dynamic model of a PEMFC has been developed and validated against experimental data in [34] and in [35], focusing on the temperature profile through the cell, produced by the reaction and due to ohmic losses and removed through convection in the channels. Steady state assessment of voltage and ohmic losses was accompanied by dynamic modelling of concentration and activation losses in [36] and the dynamic response under step current variations in [37].

The integration of the heat exchange apparatus is also important, especially for FCs operating at high temperature. Heat can be used to sustain reforming to produce hydrogen, to feed a parallel turbine cycle based on steam or an Organic Rankine Cycle (ORC) or for residential heat cogeneration in the case of low enthalpy sources. An example of integration with an ORC is reported in [13] and with a water absorption cycle is described in [38]. In addition, the dynamic simulation of hot water supply simultaneously with power generation in a house has been reported in [39].

\section{Fluid dynamic modelling}

The detailed description of the flow field at the anode and cathode is an important piece of information. It affects the distribution of reactants (and thus cell performance), but also heat and water management. Accurate description is specifically needed at the cathode side, characterised by smaller gas diffusion coefficients. If flooding should occur, gas diffusion through the gas diffusion layer and at the catalyst layer would be inhibited, with overheating and dying of the membrane. Modelling the flow pattern implied the knowledge of the geometry of the channels, their discretization into a proper mesh and the solution of the governing equations of such problem through home developed algorithms, often aided by commercial or open packages, such as Ansys Fluent $^{\oplus}$ or Open Foam ${ }^{\circledR}$.

A button SOFC has been described with a 3D Computational Fluid Dynamic (CFD) model to retrieve the temperature, current and concentration patterns in a cross section of the cell, allowing better control of the operating conditions and preventing thermal 
stress and cell damage [40]. The model was based on electrode kinetics, mass transport, and elaborated in the ANSYS ${ }^{\odot}$ Fluent environment, using a specific add-on for SOFC.

An experimental investigation supported the activity, referring to a button SOFC with a La0.8Sro. ${ }_{2} \mathrm{MnO}_{3}$ cathode and NiO-YSZ anode. The nodes of the model implemented were based on modelling fluid flow, including heat and mass transport into the channels and pores of the anode and cathode, current and potential in the solid material (including porous layers) and electrochemical reactions at the interface between the electrode and electrolyte [40]. The key steps of the model are the following.

The conservation of momentum is:

$$
\frac{\partial}{\partial t} \rho \vec{v}+\nabla \rho \vec{v} y_{i}=\nabla \overrightarrow{J_{l}}+S_{s, i}
$$

In the equation $\rho$ is the density, $v$ the velocity, $y_{i}$ the composition in mass fraction and $S_{i}$ the sink or source of the i-th species.

The charge conservation is calculated as:

$$
\begin{gathered}
\nabla i=0 \\
i=-\sigma \nabla \phi
\end{gathered}
$$

with $\sigma$ as electric conductivity and $\phi$ the Nernst potential calculated as:

$$
\phi_{\text {ideal }}=\phi^{0}+\frac{R T}{4 F} \ln \left(\frac{p_{\mathrm{H} 2} p_{\mathrm{O} 2}^{0.5}}{p_{\mathrm{H} 2 \mathrm{O}}}\right)
$$

However, the actual cell potential is calculated taking into account the jump potential and the activation over-potential and the current density is calculated through the Butler-Volmer equation.

$$
\begin{gathered}
i=i_{0, e f f}\left[e^{\frac{\alpha_{a} n \eta_{a c t, a} F}{R T}}-e^{-\frac{\alpha_{c} n \eta_{a c t, c} F}{R T}}\right] \\
\phi_{\text {cell }}=\phi_{j u m p}-\eta \\
\phi_{\text {jump }}=\phi_{\text {ideal }}-\eta_{\text {ele }}-\eta_{\text {act }, a}-\eta_{a c t, c}
\end{gathered}
$$

where $\eta_{\text {act }}$ is the activation overpotential for the anode (a) or cathode (c). Equations for heat transfer computation are also available, such as:

$$
\begin{gathered}
\frac{\partial}{\partial t} \rho E+\nabla \rho \vec{v} E+p=\nabla\left(k_{e f f} \nabla T-\sum_{j} h_{j} \overrightarrow{\jmath_{j}}+\overrightarrow{\tau_{e f f} \vec{v}}\right)+S_{h} \\
S_{h}=i^{2} R_{\text {Ohmic }} \\
E=h-\frac{p}{\rho}+\frac{v^{2}}{2} \\
h=\sum_{j} y_{j} h_{j}
\end{gathered}
$$


where $S_{h}$ is the heat source and $E$ the volumetric source. Details are reported in the original reference [40]. The model was implemented and loaded on a mesh of 3 million volume cells. The results showed increasing current density and power density for a given voltage and flowrates, and the parameters also increased with increasing flowrates (Figure 11). The concentration profiles of hydrogen and oxygen at the electrodes are also shown.

Figure 11: a) current density and b) power density variation with temperature and flowrates for a button SOFC (0.6 V). Reproduced by kind permission of Elsevier from [40].

a)

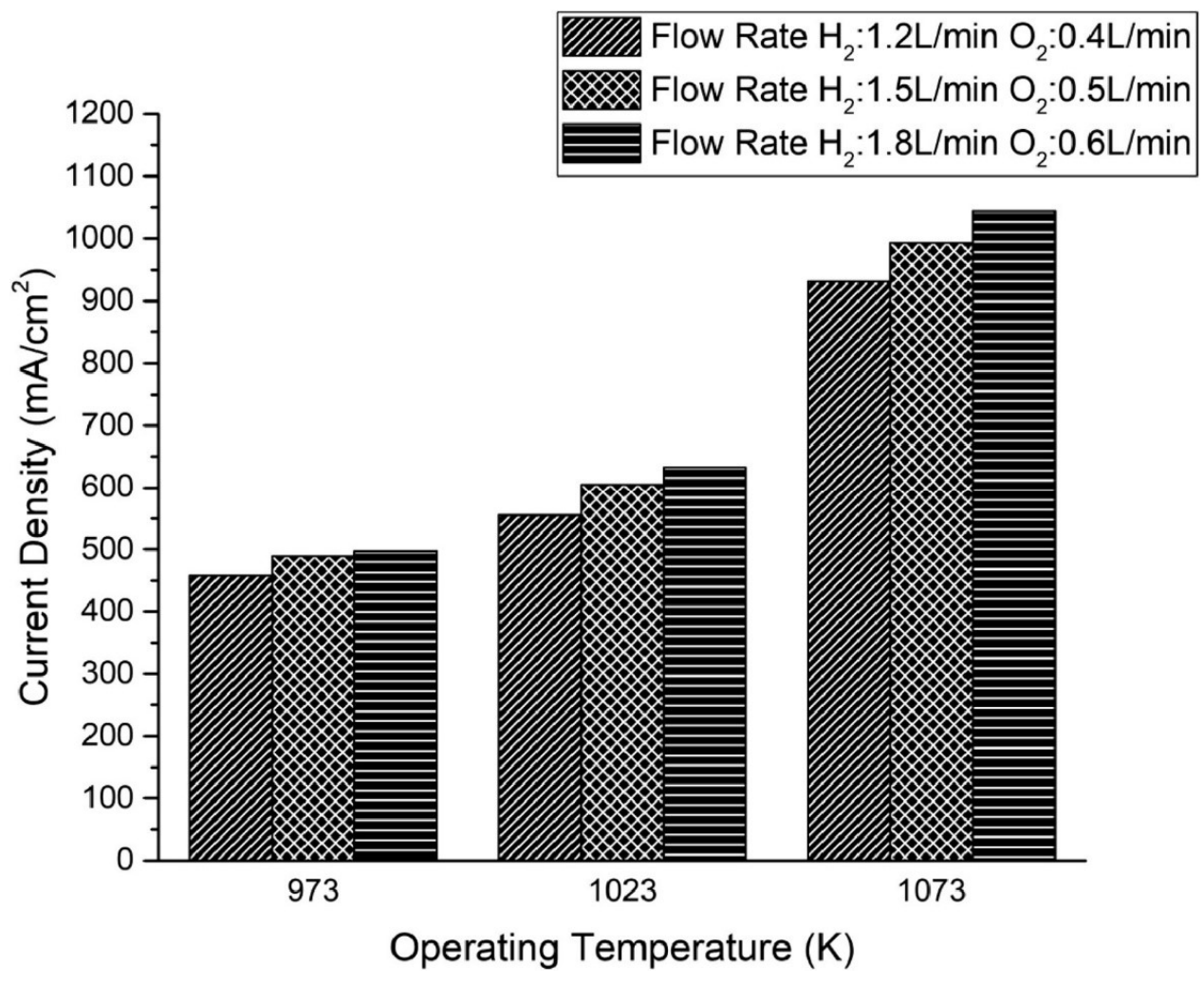

b) 


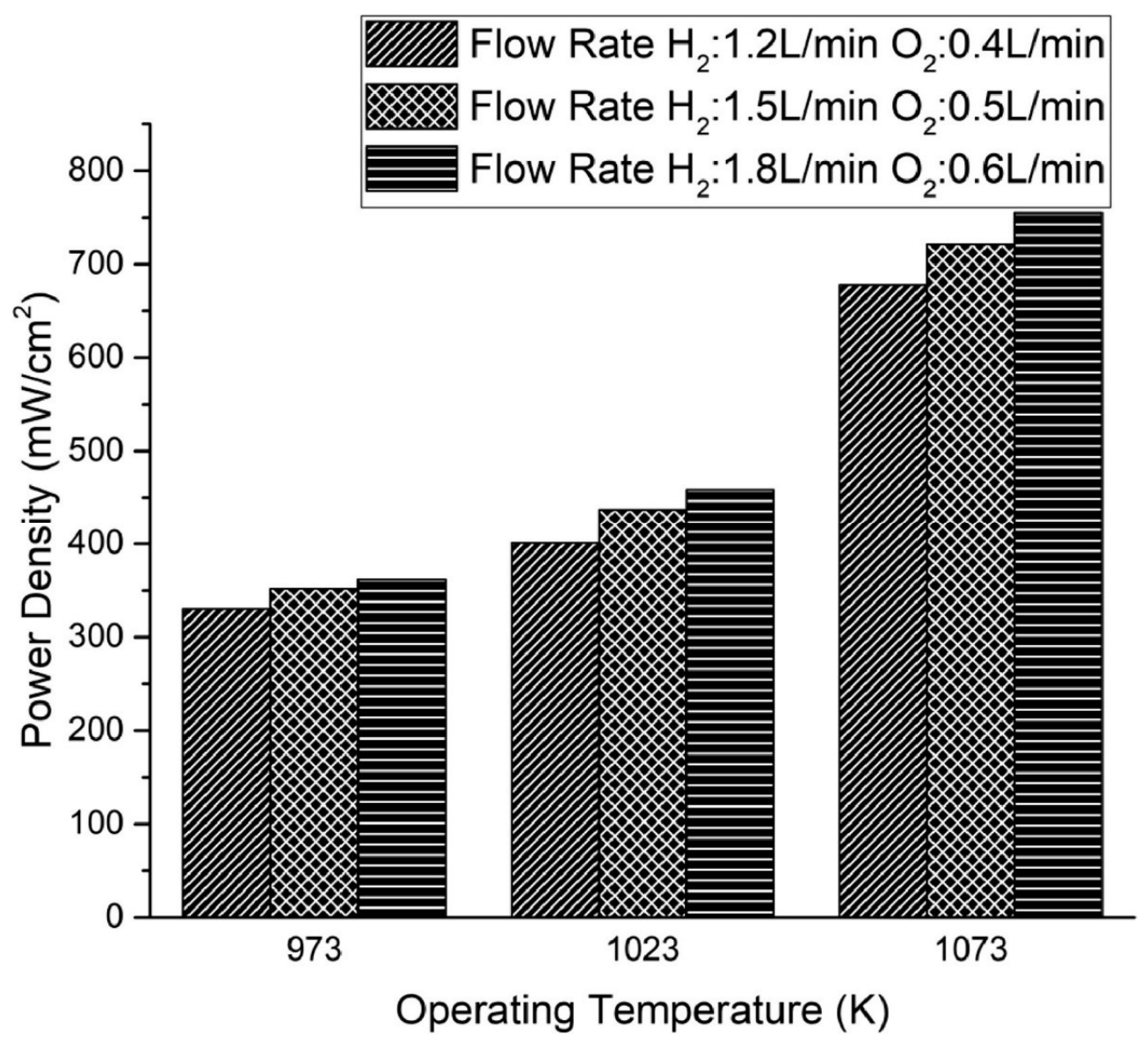

A very detailed 3-D fluid dynamic model has been developed by Atyabi et al. [41] to compare the flow pattern of oxygen between straight parallel and sinusoidal cathodic channels. CFD via finite volume and SIMPLE algorithm has been applied to model cathodic flowrate. The results showed that higher velocity was attained in the sinusoidal configuration, with increased diffusion towards the GDL, though at the expenses of higher pressure drop. Through the quantification of a uniformity index of different variables, the sinusoidal channels were characterised by more uniform oxygen mass fraction and temperature distribution, reducing the thermal stress [41].

In the same line, Kuo et al. $[42,43]$ demonstrated that a wave flow field improves mass transfer and convection, with more uniform temperature profile. As well, bio-inspired flow patterns improved uniformity of reactants and consequently power density, with respect to parallel-spiral flow [44]. Counterflow configuration led to higher membrane conductivity than co-current flow [45].

A CFD framework has been used also to model diffusion and convection in porous transport layers, such as GDL. A macroscopic control volume was developed and implemented in a finite volume code with Ansys Fluent, embedding the microscopic porous network into the mesh [10].

Transient effects are significant for mobile applications and were the focus of a 3-D CFD study of a PEMFC with a serpentine channel. A step-change in the mass flow rates ends in current and power densities increase with time at low cell voltage due to concentration losses, but negligible at high voltages [46]. 


\section{Water management}

Water management is a fundamental isse to ensure stable performance for fuel cells operating at temperature lower than $100^{\circ} \mathrm{C}$ (e.g. in PEMFC), where liquid water is expected to form and accumulate in the cell [47-49]. On one hand the use of humid inlet gases is compulsory to avoid the drying of the membrane. The conductivity of the membrane is tightly related to its water content. If the cathodic gas nearby the membrane is not saturated with vapor, the membrane may release water, decreasing its proton conductivity and adding ohmic losses. The water transport in the membrane is also further complicated by the tranport of protons across it, which occurs as hydrated ions. The existence of a water concentration gradient from the cathode to the anode can stimulate the back diffusion of water. Based on the local temperature and pressure in the pores of the cathode, water can be either in vapor or liquid state. On the other hand the water forming during the reaction must be effectively discharged from the channels to avoid accumulation and thus flooding of the cell $[50,51]$. In such a case unstable performance may be observed, with abrupt voltage change when water is expelled. If both conditions coexist periodically, the expected lifetime of the cell is shortened [52]. Furthermore, the excess water prevents the correct transport and contact between the gases and the electrodes.

The former issue can be accomplshed by including an external humidifier, in form of a heat exchanger that provides some heat and vapor to the incoming gases. This is of course an additional item that adds costs and management issues to the assembly. On the contrary, a solution has been proposed to spatially resolve the heat removal from the cell so to achieve an appropriate humidity of the gases [52]. For instance, is the temperature of the cathode is allowed to increase only gradually prodiding accurate cooling, the gas can remain saturated along the channel, without the need of external humidity supply. A model has been developed to design a proper thermal profile, neglecting pressure drop along the channel, the thickness of the gas diffusion layers and hydraulic permeation acros the membrane. The model demonstrated the possibility to use the product water to keep the gases saturated through the channel, conclusion confirmed by experimental validation [52].

Detailed models have been also developed to investigate droplets formation and discharge in the channels of a PEMFC [51]. Multiphase flow field of oxygen, hydrogen and water must be studied to optimise operation and ensure the long term stability of the device. Microchannels are designed to narrow the depth and width of the flow field and modelled usually through finite element simulation. The pore size distribution of the carbon paper affects the droplets size and shape. Smaller channels increase the droplet pressure difference and improve their discarge rate [51].

\section{Integrated fuel processors}

A dynamic model based on simulation and experimental data was developed for a stand-alone PEMFC, including a reformer, a FC and the power conditioning system [53]. A similar system was also modelled for a residential power generation unit based on methanol reforming [54-56].

Hydrogen production via steam reforming of biomass-derived compounds, such as bioethanol is getting increasing attention [57-63], including the design of integrated 
processes for fuel processing and conversion into FCs. Ethanol in particular has the advantage of being a non-toxic liquid, being flexibly reformable and its material yield and energetic input can be tuned varying the water/ethanol ratio in the reacting mixture [64]. It can also be used at low purity levels [58, 65], thus limiting the reactant cost. The catalysts for ethanol reforming are a substantially commercial reality [66, 67] and can meet wide market options, such as residential power co-generation $[68,69]$ or centralised production in biorefineries. An integrated plant for the joint electrical and thermal power production from diluted bioethanol, with a size of $8-11 \mathrm{~kW}$ (of which Pelectical $\geq 4 \mathrm{~kW}$ ) has been designed and rated, based on a PEMFC, with special emphasis on thermal integration [70-72]. This unit exploits diluted bioethanol as inexpensive feed with respect to the anhydrous pure ethanol. This point is the key for the economy of the generator and opens possibilities for thermal energy valorization.

\section{Conclusions}

Models for the description of different FC types have been derived over the years. They allow computation of the steady state or transient behaviour of the cell and can be used for the faster and inexpensive simulation of cell operation under different conditions. Simpler systems include only single cells or stacks, while more complex layouts include the fuel processor and, possibly, the connection with the grid. Failure models are also available to predict the reliability of the cells.

The thermodynamic description of the electrochemical system is available, together with kinetics for different FCs, mainly PEMFC and SOFC devices, which are the most investigated at the moment. Different overpotentials are also discussed, with the relative modelling tools. Finally, transport phenomena are accounted for through proper modelling, to estimate the efficiency of the system, but also to cope with the removal of water through the channels.

Overall, relatively easy models can be implemented with reasonably accurate predictions of the cell behaviour, allowing sizing and rating, but also optimisation in connection with fuel processors and lifetime prediction.

Funding: This research received no external funding.

Data Availability Statement: All the data are available in this paper and in the cited references.

Conflicts of Interest: The authors declare no conflict of interest. 


\section{References}

1. https://www.nrel.gov/hydrogen/

2. Tullius V, Zobel M, Dyck A (2020) Development of a Heuristic Control Algorithm for Detection and Regeneration of CO Poisoned LT-PEMFC Stacks in Stationary Applications. Energies 13:4648. https://doi.org/10.3390/en13184648

3. Beale SB, Andersson M, Boigues-Muñoz C, et al (2021) Continuum scale modelling and complementary experimentation of solid oxide cells. Prog Energy Combust Sci 85:100902. https://doi.org/10.1016/J.PECS.2020.100902

4. Kravos A, Ritzberger D, Tavcar G, et al (2020) Thermodynamically consistent reduced dimensionality electrochemical model for proton exchange membrane fuel cell performance modelling and control. J Power Sources 454:227930. https://doi.org/10.1016/J.JPOWSOUR.2020.227930

5. Mei S, Lu X, Zhu Y, Wang S (2021) Thermodynamic assessment of a system configuration strategy for a cogeneration system combining SOFC, thermoelectric generator, and absorption heat pump. Appl Energy 302:117573. https://doi.org/10.1016/J.APENERGY.2021.117573

6. Bianchi FR, Spotorno R, Piccardo P, Bosio B (2020) Solid Oxide Fuel Cell Performance Analysis through Local Modelling. Catalysts 10:519. https://doi.org/10.3390/catal10050519

7. Gupta J, Nijhawan P, Ganguli S (2021) Optimal parameter estimation of PEM fuel cell using slime mould algorithm. Int J Energy Res 45:14732-14744. https://doi.org/10.1002/er.6750

8. Alizadeh M, Torabi F (2021) Precise PEM fuel cell parameter extraction based on a self-consistent model and SCCSA optimization algorithm. Energy Convers Manag 229:113777. https://doi.org/10.1016/J.ENCONMAN.2020.113777

9. Rubio A, Agila W (2019) Dynamic Model of Proton Exchane Membrane Fuel Cells: A Critical Review and a Novel Model. 8th Int Conf Renew Energy Res Appl Brasov, Rom 353-358

10. García-Salaberri PA (2021) Modeling diffusion and convection in thin porous transport layers using a composite continuum-network model: Application to gas diffusion layers in polymer electrolyte fuel cells. Int J Heat Mass Transf 167:120824. https://doi.org/10.1016/J.IJHEATMASSTRANSFER.2020.120824

11. Zhang Y, Zhang Y, Li X, Cao G (2013) Control design of $60 \mathrm{~kW}$ PEMFC generation system for residential applications. J Zhejiang Univ Sci A 14:679-685. https://doi.org/10.1631/jzus.A1300146

12. Ahmed K, Farrok O, Rahman MM, et al (2020) Proton exchange membrane hydrogen fuel cell as the grid connected power generator. Energies 13:1-20. https://doi.org/10.3390/en13246679

13. Ansari SA, Khalid M, Kamal K, et al (2021) Modeling and simulation of a proton exchange membrane fuel cell alongside a waste heat recovery system based on the organic rankine cycle in MATLAB/SIMULINK environment. Sustain 13:1-21. https://doi.org/10.3390/su13031218 
14. Yu X, Starke MR, Tolbert LM, Ozpineci B (2007) Fuel cell power conditioning for electric power applications: a summary. IET Electr Power Appl 1:643. https://doi.org/10.1049/iet-epa:20060386

15. Mann RF, Amphlett JC, Hooper MAI, et al (2000) Development and application of a generalised steady-state electrochemical model for a PEM fuel cell. J Power Sources 86:173-180. https://doi.org/10.1016/S03787753(99)00484-X

16. Priya K, Sudhakar Babu T, Balasubramanian K, et al (2015) A novel approach for fuel cell parameter estimation using simple Genetic Algorithm. Sustain Energy Technol Assessments 12:46-52. https://doi.org/10.1016/j.seta.2015.09.001

17. Grondin-Perez B, Roche S, Lebreton C, et al (2014) Mechanistic Model versus Artificial Neural Network Model of a Single-Cell PEMFC. Engineering 06:418-426. https://doi.org/10.4236/eng.2014.68044

18. Askarzadeh A, Rezazadeh A (2011) A new artificial bee swarm algorithm for optimization of proton exchange membrane fuel cell model parameters. J Zhejiang Univ Sci C 12:638-646. https://doi.org/10.1631/jzus.C1000355

19. Askarzadeh A, Rezazadeh A (2011) A grouping-based global harmony search algorithm for modeling of proton exchange membrane fuel cell. Int J Hydrogen Energy 36:5047-5053. https://doi.org/10.1016/j.ijhydene.2011.01.070

20. El-Fergany AA, Hasanien HM, Agwa AM (2019) Semi-empirical PEM fuel cells model using whale optimization algorithm. Energy Convers Manag 201:112197. https://doi.org/10.1016/j.enconman.2019.112197

21. Fawzi M, El-Fergany AA, Hasanien HM (2019) Effective methodology based on neural network optimizer for extracting model parameters of PEM fuel cells. Int J Energy Res 43:8136-8147. https://doi.org/10.1002/er.4809

22. Kumar P, Gnanasekar S, Andrews NG, Natarajan R (2021) An integrated approach on proton exchange membrane fuel cell performance enhancement combining flower pollination algorithm and nanofluids. IET Renew Power Gener 15:2216-2227. https://doi.org/10.1049/rpg2.12156

23. Chugh S, Chaudhari C, Sonkar K, et al (2020) Experimental and modelling studies of low temperature PEMFC performance. Int J Hydrogen Energy 45:8866-8874. https://doi.org/10.1016/J.IJHYDENE.2020.01.019

24. Escobar-Yonoff R, Maestre-Cambronel D, Charry S, et al (2021) Performance assessment and economic perspectives of integrated PEM fuel cell and PEM electrolyzer for electric power generation. Heliyon 7:e06506. https://doi.org/10.1016/j.heliyon.2021.e06506

25. Chippar P, Ju H (2013) Numerical modeling and investigation of gas crossover effects in high temperature proton exchange membrane (PEM) fuel cells. Int J Hydrogen Energy 38:7704-7714. https://doi.org/10.1016/J.IJHYDENE.2012.07.123

26. Costamagna P, Grosso S, Travis R, Magistri L (2015) Integrated planar solid oxide fuel cell: Steady-state model of a bundle and validation through single tube experimental data. Energies 8:13231-13254. https://doi.org/10.3390/en81112364 
27. Costamagna P, De Giorgi A, Gotelli A, et al (2016) Fault diagnosis strategies for SOFC-based power generation plants. Sensors (Switzerland) 16:1-17. https://doi.org/10.3390/s16081336

28. Costamagna P, De Giorgi A, Moser G, et al (2019) Data-driven techniques for fault diagnosis in power generation plants based on solid oxide fuel cells. Energy Convers Manag 180:281-291. https://doi.org/10.1016/J.ENCONMAN.2018.10.107

29. Costamagna P, De Giorgi A, Moser G, et al (2019) Data-driven fault diagnosis in SOFC-based power plants under off-design operating conditions. Int J Hydrogen Energy 4:29002-29006. https://doi.org/10.1016/J.IJHYDENE.2019.09.128

30. Costamagna P, De Giorgi A, Magistri L, et al (2016) A Classification Approach for Model-Based Fault Diagnosis in Power Generation Systems Based on Solid Oxide Fuel Cells. IEEE Trans Energy Convers 31:676-687. https://doi.org/10.1109/TEC.2015.2492938

31. Eichhorn Colombo KW, Kharton V V. (2021) Reliability analysis of a multi-stack solid oxide fuel cell from a systems engineering perspective. Chem Eng Sci 238:116571. https://doi.org/10.1016/J.CES.2021.116571

32. Ritchie AJ, Brouwer J (2018) Design of fuel cell powered data centers for sufficient reliability and availability. J Power Sources 384:196-206. https://doi.org/10.1016/j.jpowsour.2018.02.059

33. Azri M, Mubin ANA, Ibrahim Z, et al (2016) Mathematical Modelling for Proton Exchange Membrane Fuel Cell (PEMFC). J Theor Appl Inf Technol 86:409-419

34. Benchouia N, Hadjadj A, Derghal A, et al (2013) Modeling and validation of fuel cell PEMFC-accepté le 30 juin 2013). Rev des Energies Renouvelables 16:365-377

35. Acedo-Valencia J, Sierra J, Figueroa-Ramírez S, et al Numerical study of heat transfer in a PEM fuel cell with different flow-fields. In: In Proceedings of the XV International Congress of the Mexican Hydrogen

36. Xue XD, Cheng KWE, Sutanto D (2006) Unified mathematical modelling of steady-state and dynamic voltagecurrent characteristics for PEM fuel cells. Electrochim Acta 52:1135-1144. https://doi.org/10.1016/j.electacta.2006.07.011

37. Zhao J, Jian Q, Luo L, et al (2018) Dynamic behavior study on voltage and temperature of proton exchange membrane fuel cells. Appl Therm Eng 145:343-351. https://doi.org/10.1016/j.applthermaleng.2018.09.030

38. Guo X, Zhang H, Zhao J, et al (2019) Performance evaluation of an integrated high-temperature proton exchange membrane fuel cell and absorption cycle system for power and heating/cooling cogeneration. Energy Convers Manag 181:292-301. https://doi.org/10.1016/j.enconman.2018.12.024

39. Tripodi A, Bahadori E, Ramis G, Rossetti I (2019) Feasibility assessment, process design and dynamic simulation for cogeneration of heat and power by steam reforming of diluted bioethanol. Int J Hydrogen Energy 44:2-22. https://doi.org/10.1016/j.ijhydene.2018.02.122

40. Alhazmi N, Almutairi G, Alenazey F, AlOtaibi B (2021) Three-dimensional computational fluid dynamics 
modeling of button solid oxide fuel cell. Electrochim Acta 390:138838. https://doi.org/10.1016/J.ELECTACTA.2021.138838

41. Atyabi SA, Afshari E (2019) A numerical multiphase CFD simulation for PEMFC with parallel sinusoidal flow fields. J Therm Anal Calorim 135:1823-1833. https://doi.org/10.1007/S10973-018-7270-3

42. Kuo J-K, Chen C-K (2007) The effects of buoyancy on the performance of a PEM fuel cell with a wave-like gas flow channel design by numerical investigation. Int J Heat Mass Transf 50:4166-4179. https://doi.org/10.1016/j.ijheatmasstransfer.2007.02.039

43. Kuo J-K, Yen T-H, Chen C-K (2008) Three-dimensional numerical analysis of PEM fuel cells with straight and wave-like gas flow fields channels. J Power Sources 177:96-103. https://doi.org/10.1016/j.jpowsour.2007.11.065

44. Roshandel R, Arbabi F, Moghaddam GK (2012) Simulation of an innovative flow-field design based on a bio inspired pattern for PEM fuel cells. Renew Energy 41:86-95. https://doi.org/10.1016/j.renene.2011.10.008

45. Ge S-H, Yi B-L (2003) A mathematical model for PEMFC in different flow modes. J Power Sources 124:1-11. https://doi.org/10.1016/S0378-7753(03)00584-6

46. Kupeli S, Celik E, Karagoz I (2021) Response of a proton exchange membrane fuel cell to step changes in mass flow rates. Fuel Cells 1-9. https://doi.org/10.1002/fuce.202000170

47. Zawodzinski TA, Neeman M, Sillerud LO, Gottesfeld S (1991) Determination of water diffusion coefficients in perfluorosulfonate ionomeric membranes. J Phys Chem 95:6040-6044. https://doi.org/10.1021/J100168A060

48. Fuller TF, Newman J (1993) Water and Thermal Management in Solid-Polymer-Electrolyte Fuel Cells. J Electrochem Soc 140:1218-1225. https://doi.org/10.1149/1.2220960

49. Nguyen T V., White RE (1993) A Water and Heat Management Model for Proton-Exchange-Membrane Fuel Cells. J Electrochem Soc 140:2178-2186. https://doi.org/10.1149/1.2220792

50. Su S, Liang J, Luo Y, et al (2021) A new water management system for air-breathing direct methanol fuel cell using superhydrophilic capillary network and evaporation wings. Energy Convers Manag 246:114665. https://doi.org/10.1016/J.ENCONMAN.2021.114665

51. Zhang R, Yang B, Lei X, et al (2022) Droplets dynamics theory and micro-flow field experiments of improving self-humidifying feature and maximum power density in fuel cells. Chem Eng J 429:131974. https://doi.org/10.1016/J.CEJ.2021.131974

52. Tolj I, Bezmalinovic D, Barbir F (2011) Maintaining desired level of relative humidity throughout a fuel cell with spatially variable heat removal rates. Int J Hydrogen Energy 36:13105-13113. https://doi.org/10.1016/J.IJHYDENE.2011.07.078

53. El-Sharkh MY, Rahman A, Alam MS, et al (2004) Analysis of Active and Reactive Power Control of a StandAlone PEM Fuel Cell Power Plant. IEEE Trans Power Syst 19:2022-2028. https://doi.org/10.1109/TPWRS.2004.836191 
54. El-Sharkh MY, Rahman A, Alam MS, et al (2004) A dynamic model for a stand-alone PEM fuel cell power plant for residential applications. J Power Sources 138:199-204. https://doi.org/10.1016/j.jpowsour.2004.06.037

55. Iulianelli A, Ribeirinha P, Mendes A, Basile A (2014) Methanol steam reforming for hydrogen generation via conventional and membrane reactors: A review. Renew Sustain Energy Rev 29:355-368. https://doi.org/10.1016/j.rser.2013.08.032

56. Wang S, Wang S (2006) Exergy analysis and optimization of methanol generating hydrogen system for PEMFC. Int J Hydrogen Energy 31:1747-1755. https://doi.org/10.1016/j.ijhydene.2005.12.005

57. Xuan J, Leung MKH, Leung DYC, Ni M (2009) A review of biomass-derived fuel processors for fuel cell systems. Renew Sustain Energy Rev 13:1301-1313. https://doi.org/10.1016/j.rser.2008.09.027

58. Remiro A, Valle B, Oar-arteta L, et al (2014) Hydrogen production by steam reforming of bio-oil and bio-ethanol mixtures in a continuous thermal-catalytic process. Int J Hydrogen Energy 39:6889-6898. https://doi.org/10.1016/j.ijhydene.2014.02.137

59. Zou J, Yang H, Zeng Z, et al (2016) Hydrogen production from pyrolysis catalytic reforming of cellulose in the presence of K alkali metal. Int J Hydrogen Energy 41:10598-10607. https://doi.org/10.1016/j.ijhydene.2016.04.207

60. Alvarez J, Kumagai S, Wu C, et al (2014) Hydrogen production from biomass and plastic mixtures by pyrolysisgasification. Int J Hydrogen Energy 39:10883-10891. https://doi.org/10.1016/j.ijhydene.2014.04.189

61. Ma Z, Xiao R, Zhang H (2017) Catalytic steam reforming of bio-oil model compounds for hydrogen-rich gas production using bio-char as catalyst. Int J Hydrogen Energy 42:3579-3585. https://doi.org/10.1016/j.ijhydene.2016.11.107

62. Cheekatamarla PK, Finnerty CM (2008) Synthesis gas production via catalytic partial oxidation reforming of liquid fuels. Int J Hydrogen Energy 33:5012-5019. https://doi.org/10.1016/j.ijhydene.2008.07.003

63. Ni M, Leung DYC, Leung MKH (2007) A review on reforming bio-ethanol for hydrogen production. Int J Hydrogen Energy 32:3238-3247. https://doi.org/10.1016/j.ijhydene.2007.04.038

64. Tripodi A, Compagnoni M, Ramis G, Rossetti I (2017) Process simulation of hydrogen production by steam reforming of diluted bioethanol solutions: Effect of operating parameters on electrical and thermal cogeneration by using fuel cells. Int J Hydrogen Energy 42:23776. https://doi.org/10.1016/j.ijhydene.2017.04.056

65. García-díez E, García-labiano F, Diego LF De, et al (2016) Optimization of hydrogen production with CO2 capture by autothermal chemical-looping reforming using different bioethanol purities. Appl Energy 169:491498. https://doi.org/10.1016/j.apenergy.2016.02.061

66. Akpan E, Akande A, Aboudheir A, et al (2007) Experimental, kinetic and 2-D reactor modeling for simulation of the production of hydrogen by the catalytic reforming of concentrated crude ethanol ( CRCCE ) over a Nibased commercial catalyst in a packed-bed tubular reactor. Chem Eng Sci 62:3112-3126. https://doi.org/10.1016/j.ces.2007.03.006 
67. Mathure P V., Ganguly S, Patwardhan A V., Saha RK (2007) Steam reforming of ethanol using a commercial nickel-based catalyst. Ind Eng Chem Res 46:8471-8479. https://doi.org/10.1021/ie070321k

68. Lanzini A, Santarelli M, Orsello G (2010) Residential Solid Oxide Fuel Cell Generator Fuelled by Ethanol: Cell, Stack and System Modelling with a Preliminary Experiment. Fuel Cells 654-675. https://doi.org/10.1002/fuce.201000004

69. Farra N, Tzanetakis T, Thomson MJ (2012) Experimental Determination of the Efficiency and Emissions of a Residential Microcogeneration System Based on a Stirling Engine and Fueled by Diesel and Ethanol. Energy \& Fuels 26:889-900. https://doi.org/dx.doi.org/10.1021/ef201468j

70. Tripodi A, Pizzonia A, Bahadori E, Rossetti I (2018) Integrated Plant Layout for Heat and Power Cogeneration from Diluted Bioethanol. ACS Sustain Chem Eng 6:5358-5369. https://doi.org/10.1021/acssuschemeng.8b00144

71. Rossetti I, Compagnoni M, Torli M (2015) Process simulation and optimisation of H2 production from ethanol steam reforming and its use in fuel cells. 1. Thermodynamic and kinetic analysis. Chem Eng J 281:1024-1035. https://doi.org/10.1016/j.cej.2015.08.025

72. Rossetti I, Compagnoni M, Torli M (2015) Process simulation and optimization of H 2 production from ethanol steam reforming and its use in fuel cells . 2 . Process analysis and optimization. Chem Eng J 281:1036-1044. https://doi.org/10.1016/j.cej.2015.08.045 